\title{
The retardant effect of 2-Tridecanone, mediated by Cytochrome P450, on the Development of Cotton bollworm, Helicoverpa armigera
}

\author{
Lei Zhang ${ }^{1}$, Yao Lu', Min Xiang ${ }^{1}$, Qingli Shang ${ }^{2}$ and Xiwu Gao ${ }^{1 *}$
}

\begin{abstract}
Background: Plant allelochemicals act as toxins, inhibitors of digestion, and deterrents that affect the fecundity of insects. These compounds have attracted significant research attention in recent decades, and much is known about the effects of these xenobiotic plant secondary metabolites on insect development. To date, although ecological interactions between xenobiotic plant secondary chemicals that retard insect growth have been observed in many species, it remains unclear how particular allelochemicals influence insect development in a life stage-dependent manner.

Results: We found that 2-tridecanone can affect insect development; this effect appears similar to the symptoms induced by the physiological imbalance between juvenile and molting hormones in cotton bollworm. We later detected that a decrease in the concentration of 20-hydroxyecdysone occurred alongside the observed symptoms. We next identified the transcriptome of Helicoverpa armigera and eightdigital gene expression libraries for shading light on how 2-tridecanone retarded the development of cotton bollworm. The expression of CYP314A1, CYP315A1, CYP18A1, CYP307A1, and CYP306A1 (unigenes 16487, 15409, 40026, 41217, 35643, 16953, 8199, 13311, and 13036) were found to be induced by 2-tridecanone; these are known to be related to the biosynthesis or metabolism of 20-hydroxyecdysone. Expression analysis and RNA interference studies established that the retardant effect of 2-tridecanone on the development of cotton bollworm is mediated by P450 genes.
\end{abstract}

Conclusions: The candidate P450 gene approach described and exploited here is useful for identifying potential causal genes for the influence of plant allelochemicals on insect development.

Keywords: Helicoverpa armigera, Cytochrome P450, Plant allelochemicals, Insect development, Transcriptome

\section{Background}

Co-evolution strategies are a common phenomenon in herbivorous insect-plant interactions [1,2]. Insects employ various strategies to increase their performance and fitness, while plants also develop efficient strategies to defend against particular insects [3]. Host plants can produce various allelochemicals to defend against the damage of herbivorous insects [4-6]. Plant allelochemicals

\footnotetext{
* Correspondence: gaoxiwu@263.net.cn

'Department of Entomology, China Agricultural University, Beijing 100193,

People's Republic of China

Full list of author information is available at the end of the article
}

possess beneficial or detrimental effects on the target pests; allelochemicals with negative allelopathic effects are an important part of plant defense against herbivory $[7,8]$. These compounds can influence the growth, survival, and reproduction of other organisms. For example, the phenolic aldehyde gossypol can retard the developmental of the cotton bollworm, Helicoverpa armigera (H. armigera) [6]. The resistance of wild tomato (Lycopersicon hirsutum $f$. glabratum) to several arthropods has been shown to be related to the presence of high contencentrations of 2-tridecanone (2-TD) in leaves [5, 9]. 2-TD can stimulate ecdysone 20-monooxygenase activity 
in Spodoptera frugiperda [10]. 2-TD in wild tomato can defense Manduca sexta and also plays an important role in the plant resistance to Leptinotarsa decemlineate. 2-TD is also known to induce an enhanced level of tolerance to the carbamate insecticide carbaryl in Heliothis zea [9]. Up to now, although the phenomena of plant allelochemicals retarding the development of insects has been found in many species, details remain unclear about the life-stage dependent manner and pathway of allelochemicals to influence the insect development.

Insect pests have evolved various strategies with which to respond to allelochemicals from host plants [6]. Cytochrome P450 enzymes are a major source of adaptation to plant defense mechanisms in insects [11, 12]. Plant allelochemicals are known to induce the expression of various cytochrome $\mathrm{P} 450$ genes in insects. The cotton bollworm is one of the most polyphagous and cosmopolitan pest species in the world. Many studies have demonstrated that the expression levels of cotton bollworm cytochrome $\mathrm{P} 450$ genes can be induced by plant allelochemicals [12-14]. The expression of CYP9A subfamily and CYP6AE14 genes can be induced by gossypol $[12,15]$. The expression of CYP6AE, CYP9A, and CYP6B subfamily transcripts can be induced by xanthotoxin [16, 17]. 2-TD can significantly induce the expression of CYP6B6 [14].

High levels of P450 gene expression are typically thought to coincide with an increased ability to metabolize exogenous compounds. Many studies have focused on detoxification enzymes that can metabolize plant natural products [18-21]. Cytochrome P450 enzymes not only act as xenobiotic detoxification agents, but also play pivotal roles in various physiological processes including the biosynthesis and metabolism of 20-hydroxyecdysone (20E) and juvenile hormone $(\mathrm{JH})$, which are the major modulators of developmental processes that result in molting and metamorphosis [22].

We found that 2-TD can affect insect development, and this type of effect was similar to the symptoms induced by the physiological imbalance between juvenile and molting hormones in cotton bollworm. We later discovered that a decrease in the concentration of $20 \mathrm{E}$ occurred alongside the observed symptoms. We then profiled the transcriptome of Helicoverpa armigera and used eight digital gene expression (DGE) libraries for shading light on how 2-TD retarded the development of cotton bollworm. These results should help to deepen our understanding of how plant allelochemicals influence insect development.

\section{Results}

\section{Effect of 2-TD on the development of $H$. armigera}

$6^{\text {th }}$ instar larvae were fed an artificial diet containing 2TD $(10 \mathrm{mg} / \mathrm{g}, \mathrm{W}: \mathrm{W})$ to evaluate the effects of 2-TD on development. $10 \mathrm{mg} / \mathrm{g} 2-\mathrm{TD}$ is a sublethal dosage that was selected based on our studies (Additional file 1). The pupation time of the treated group $(8.4 \mathrm{~d} \pm 2.01)$ was obviously longer than that of the control $(6.1 \mathrm{~d} \pm 1.67)$ (Table 1). The larval weight on the $1^{\text {st }}$ day of treatment with 2-TD decreased significantly compared to the control group, and the pupae weight at treatment day 10 was significantly lower than that of the control group (Table 1). The pupation rate and the adult emergence rate was significantly lower in the 2-TD treated group as compared to the untreated group (Table 1). The 20E titer in larvae was measured at $24 \mathrm{~h}$. The $20 \mathrm{E}$ titer after treatment was suppressed to a level that was only $57 \%$ of the control level (Table 1). The adult emergence rate in the treatment group was significantly lower than that of the control (Table 1).

\section{Sequencing and sequence assembly of the $H$. armigera transcriptome}

The effects of 2-TD on larval development are likely complicated and may involve several pathways and related genes. We constructed a transcriptome library of $H$. armigera with Illumina sequencing technology. The library contained 43,756,144 clean reads (101 bp + $101 \mathrm{bp}$ ) with an accumulated length of 4,419,370,544 nucleotides (nt) $(\mathrm{Q} 20=98.07 \%)$, de novo assembly generated a total of 93,896 non-redundant transcripts, with a median N50 length of $597 \mathrm{bp}$, and finally the total number of assembled unigenes is 42,463, the median N50 length of these unigenes is $695 \mathrm{bp}$ (Additional file 2). All unigenes were compared with the nonredundant (nr) NCBI protein database for functional annotation using BLASTX software with an e-value cutoff of $1 \mathrm{e}^{-5}$. A total of 19,382 (45.6\% of all unigenes) distinct sequences matched known genes, the species distribution of unigene BLASTX matches against the nr protein database show in Additional file 3. For further quantitative assessment of

Table 1 Effect of 2-TD on larval development

\begin{tabular}{llccccc}
\hline Treatment group & Pupation time $(\mathrm{d})$ & Pupae weight $(\mathrm{g})$ & ${ }^{*}$ Weight gain rate (\%) & $\begin{array}{l}* * 20 \mathrm{E} \text { titers gain rate after } \\
\text { treated for } 24 \mathrm{~h}(\%)\end{array}$ & Pupation rate & Adult emergence \\
\hline Control & $6.1 \mathrm{~d} \pm 1.67^{\mathrm{b}}$ & $0.243 \pm 0.056^{\mathrm{a}}$ & $4.112 \pm 1.578^{\mathrm{a}}$ & $-0.75 \% \pm 0.151^{\mathrm{a}}$ & $83.33 \%$ & $68.0 \%$ \\
2-TD & $8.4 \mathrm{~d} \pm 2.01^{\mathrm{a}}$ & $0.192 \pm 0.049^{\mathrm{b}}$ & $1.980 \pm 1.619^{\mathrm{b}}$ & $-32.58 \% \pm 0.21^{\mathrm{b}}$ & $45 \%$ & $22.2 \%$ \\
\hline
\end{tabular}

*Weight gain rate, the larval weight gain rate $24 \mathrm{~h}$ post-treatment

${ }^{*} 20 \mathrm{E}$ titer gain rate $=$ [(the concentration of $20 \mathrm{E}$ after 2-TD treatment- the concentration of 20E before 2-TD treatment) / the concentration of 20E before 2-TD treatment $\times 100 \%$. Each column sharing the same superscript letter (a or b) for both treatment groups was not significantly different at $P>0.05$ 
the assembly and annotation completeness, we applied the software tool BUSCO (Benchmarking Universal SingleCopy Orthologs), which is based on evolutionarily informed expectations of gene content, with default settings. Out of 2675 single copy orthologs for arthropods our assembly is $27 \%$ complete (663 Complete and single-copy BUSCOs, 49 Complete and duplicated BUSCOs ), while $19 \%$ of contigs are fragmented (510 BUSCOs) and 54\% are missing (1453 BUSCOs), the BUSCO analysis results show in Additional file 4. Assignments of clusters of orthologous groups (COG) were used to predict and classify the possible functions of the unigenes (Additional file 5. Among the 25 COG categories, the cluster for 'General function prediction' represented the largest group $(1421,19.1 \%)$ followed by 'Translation, ribosomal structure and biogenesis' $(724,9.76 \%)$ and 'Replication, recombination and repair' $(683,9.21 \%)$ (Additional file 5). Common gene ontology (GO) annotation was used to classify the putative functions of the $H$. armigera unigenes (Additional file 6). Pathway analysis of the unigenes was conducted using the Kyoto Encyclopedia of Genes and Genomes (KEGG) annotation system.

\section{P450 sequence alignment and phylogenetic analyses}

In our study, 153 putative P450 unigene sequences were annotated by searching the nr NCBI protein database using BLASTX. 94 long P450 unigene sequences within 153 putative $\mathrm{P} 450$ unigene sequences and 47 full-length P450 sequences from $B$. mori were used to construct a phylogenetic tree (Additional file 7). The annotated P450 unigenes in the tree belonged to the CYP2, CYP3 (including CYP6 and CYP9), CYP4, and the mitochondrial CYP (mito.CYP) clans [23]. Among the 153 predicted $\mathrm{P} 450$ unigenes in $H$. armigera, $11,11,80$, and 48 unigenes were classified into the mito.CYP, CYP2, CYP3, and CYP4 clans, respectively.

\section{Comparison of P450 gene expression profiles at different developmental stages}

In order to determine the P450 genes involved with the effects of 2-TD on larval development, eight DGE libraries were constructed to identify unigene expression profiles for shading light on how 2-tridecanone inhibited retarded the development of cotton bollworm. After removing low-quality reads, each library generated approximately eight million clean reads. Among these clean reads, 5.8-7.3 million reads were mapped to unigenes in transcriptome libraries. The Q20 ranged from 85.57 to $97.56 \%$ (Additional file 8). qPCR was used to confirm 34 unigenes expression profile results. Compared with DGE libraries results, the accuracy of these P450 unigenes expression detected by qPCR is up to 94\% (Additional file 9, Additional file 10).

Figure 1a and $\mathrm{b}$ show the summed expression of P450 unigenes and the numbers of P450 unigenes (including those of the CYP2, CYP3, CYP4 and moti. CYP clans) in the different development stages. The total expression amount and the numbers of P450 unigenes was higher in larvae than in the egg and adult samples, with the highest total expression level of P450s occurring in $3^{\text {rd }}$ instar larvae. During the transformation from eggs to larvae, the percentage of expressed CYP4 clan unigenes sharply increased from 6.4 to $71.8 \%$, while the CYP3, CYP2, and moti. CYP clan unigenes decreased significantly from $82.4,2.4$, and $8.8 \%$ to $24.2,1.0$, and $3.0 \%$ respectively. During the transformation from larvae to pupae, the percentage of expressed annotated CYP4, CYP2 and moti. CYP clan unigenes increased dramatically from $47.3,1.1$, and $3.2 \%$ to $57,3.7$, and $9.5 \%$, respectively; the percentage of expressed CYP3 clan unigenes decreased from 48.4 to $29.8 \%$ during this transition (Fig. 2) During the transformation from pupae to adults, the percentage of expressed annotated CYP4, CYP2 and moti. CYP clan unigenes decreased dramatically from $57,3.7$, and $9.5 \%$ to $24,1.9$, and $5.1 \%$, respectively, while the percentage of expressed CYP3 clan unigenes increased from 29.8 to $69.1 \%$ (Fig. 2). All the expression of the 153 P450 unigenes in different DGE library were listed in Additional file 11.

Among the 153 annotated P450 unigene sequences, the expression of 150 unigenes (98.1\%) were detected in at least one DGE library. Three P450 unigenes were not detected in any DGE library; either these were not expressed in the particular life stages that we examined or these were possibly pseudogenes. Among the expressed P450 unigenes, 33\% unigenes (55 sequences) were expressed in all
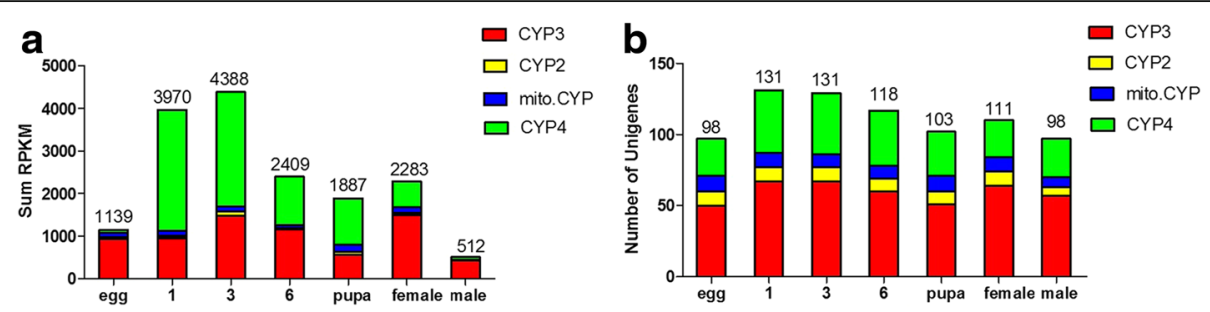

Fig. 1 The DGE library data for the expression of P450 unigenes in different development stages. a Sum expression of P450s in larvae at different developmental stages. $\mathbf{b}$ The numbers of P450 unigenes at different development stages. 1: $1^{\text {st }}$ instar larvae; $3: 3^{\text {rd }}$ instar larvae; 6: $6^{\text {th }}$ instar larvae 


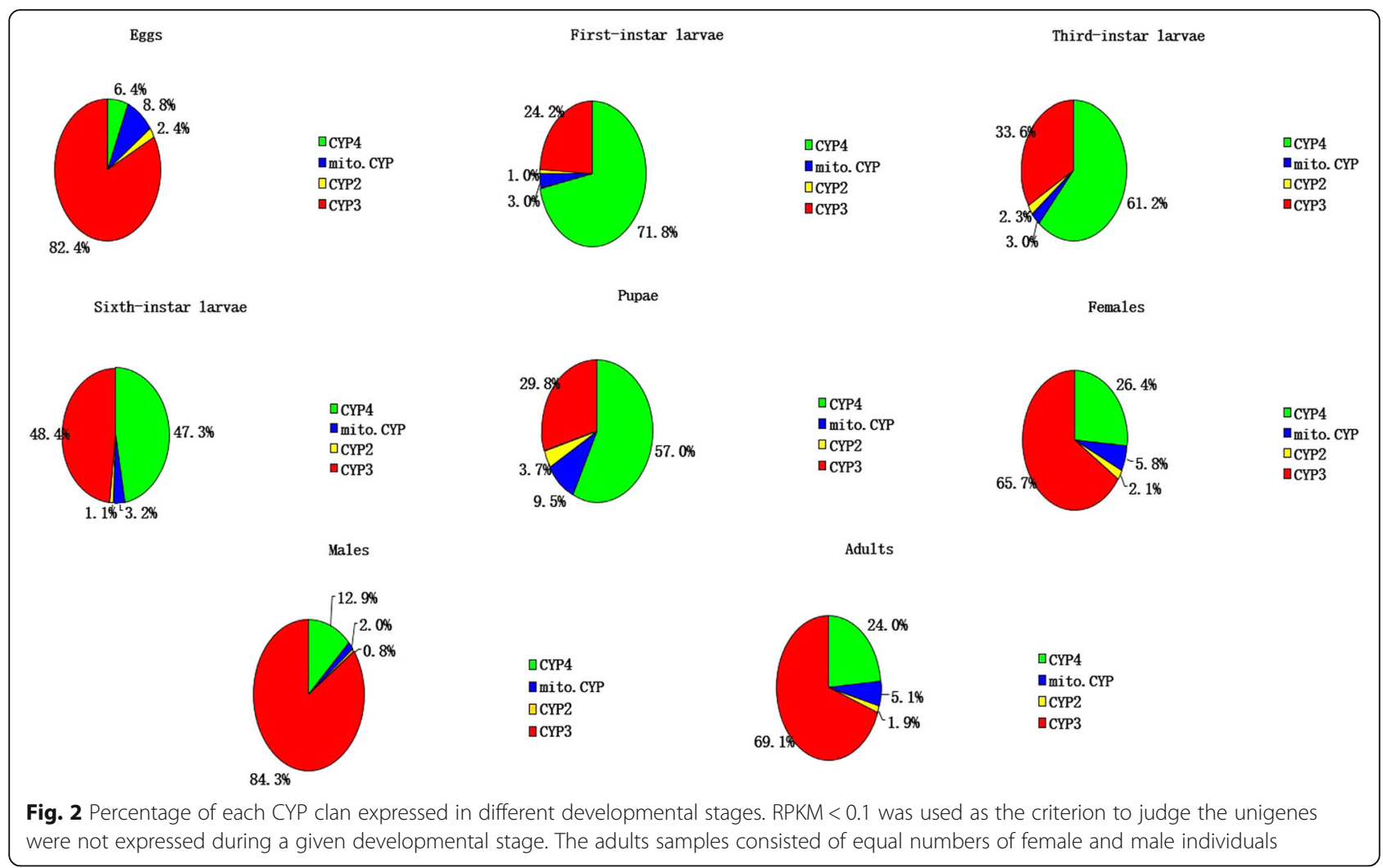

life stages (Fig. 3). Some P450 unigenes were specifically expressed at a particular developmental stage: eight P450 genes were specifically expressed in larvae, all of these belonged to the CYP3 or CYP4 clans. We found one specific P450 unigene that was only expressed in eggs. Likewise, a single unigene was expressed specifically in the pupae stage. Three P450 unigenes were expressed only in females. All these specifically expressed P450 unigenes belonged to the CYP3 or CYP4 clans (Table 2).

\section{Effect of 2-TD on the expression of P450 genes}

Figure 4 shows the total expression levels of P450 unigenes and the numbers of P450 unigenes observed in the DGE libraries of $6^{\text {th }}$ instar larvae treated by 2-TD for $24 \mathrm{~h}$ compared with the control. The total expression levels of P450 unigenes in the larvae treated by 2-TD was 2.6 fold higher than the control group (Fig. 4a). There were more P450 unigenes expressed in the 2-TD-treated group than in the control larvae; the additional two P450 unigenes belonged to the CYP3 clan (Fig. 4b). The percentages of expressed CYP3 and CYP2 clan unigenes were obviously higher in the 2-TD-treated group (64.2 and $2.8 \%$ ) than in the control (48.4 and $1.1 \%$, respectively), while the percentages of CYP4 and mito.CYP clan unigenes were higher in the control (47.3 and 3.2\%) than in the 2-TD-treated group (31.3 and 1.7\%) (Fig. 4c and d).
An absolute value of $\log _{2}$ Ratio $\geq 1$ were used as thresholds to judge the differences of gene expression levels. 49 annotated P450 unigenes were up-regulated, and 22 P450 unigenes were down-regulated in larva treated by 2-TD, as compared to the control group. 7 of these annotated $\mathrm{P} 450$ unigenes belonged to the CYP2 clan and 7 of these P450 unigenes were classified into the mito.CYP clan; none of these 14 unigenes were uniquely expressed in a particular developmental stage. However, 15 unigenes from the CYP3 and CYP4 clans were specifically expressed in a particular stage of $H$. armigera development (Table 3 ).

\section{2-TD-induced P450 genes related to hormone biosynthesis and metabolism}

Pathway analysis of the unigenes was conducted using the Kyoto Encyclopedia of Genes and Genomes (KEGG) annotation system. To confirm the unigenes expression profile results, the expression of $\mathrm{P} 450$ unigenes induced by 2-TD that related to hormone metabolism was analyzed with Real-Time qPCR (Additional file 9). Figure 4 illustrates 2-TD affects the biosynthesis and metabolism of insect hormones ( $\mathrm{JH}$ and molting hormone). The expression of four $\mathrm{P} 450$ are suppressed by 2-TD treatment: CYP307A1 (unigenes 8199, 13311), CYP306A1 (unigenes 13036), CYP314A1 (unigenes 15409), and CYP315A1 (unigenes 40026), these down-regulated genes are shown with solid blue lines in Fig. 4. The expression of two 


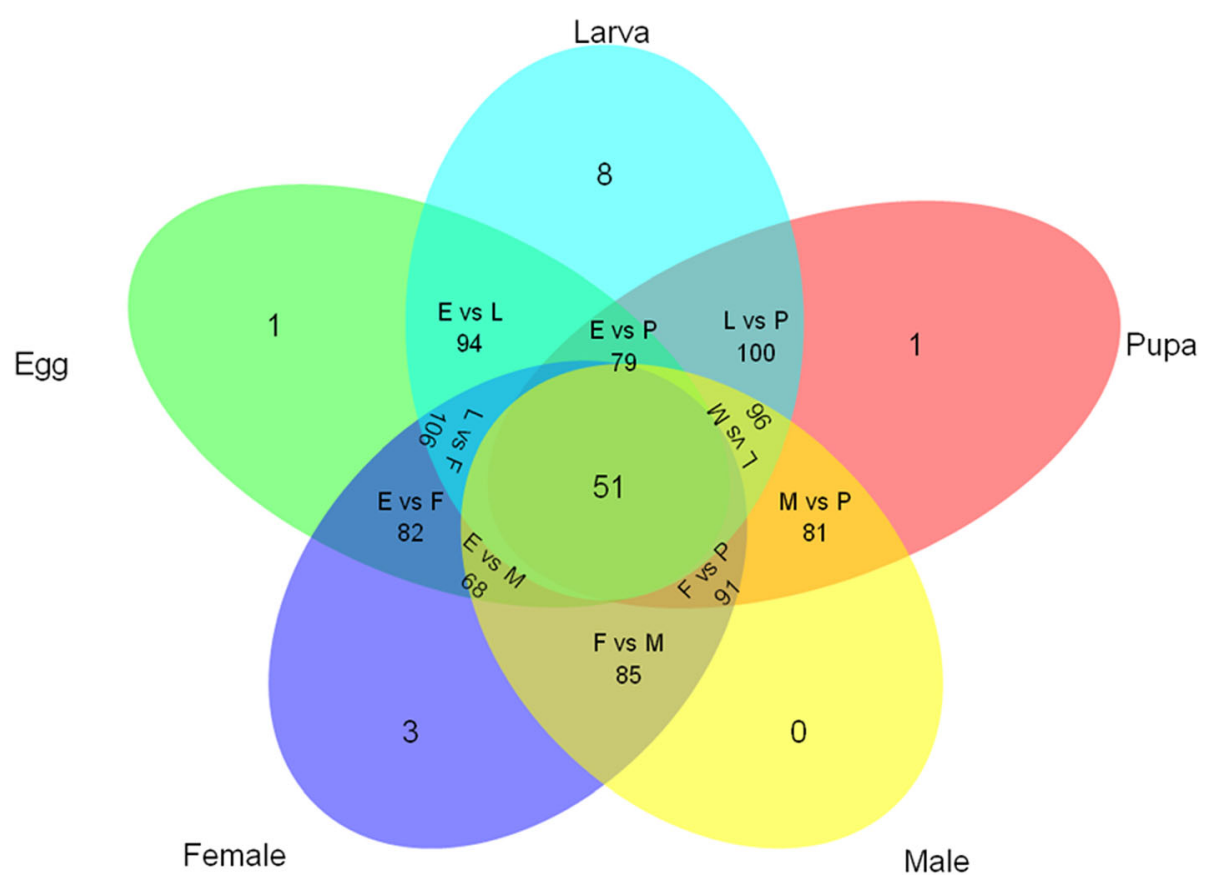

Fig. 3 Numbers of P450 unigenes expressed in a developmental stage-specific manner. RPKM $<0.1$ was used as the criterion to judge the unigenes were not expressed in a given developmental stage. E: eggs; L: larvae; P: pupae; M: males; F: females

Table 2 P450 genes expressed at specific developmental stages

\begin{tabular}{|c|c|c|c|c|c|c|}
\hline Family & Stage & $\begin{array}{l}\text { Gene } \\
\text { number }\end{array}$ & Clan & $\begin{array}{l}\text { Homologous } \\
\text { genes }\end{array}$ & $\begin{array}{l}\% \text { similarity, } \\
\text { organisms }\end{array}$ & $\mathrm{RPKM}^{\mathrm{b}}$ \\
\hline \multirow[t]{13}{*}{$\mathrm{P} 450 \mathrm{~s}^{\mathrm{a}}$} & Egg & 32583 & CYP3 & 6AX1.6B3 & $\begin{array}{l}82 \%, N . \\
\text { vitripennis }\end{array}$ & 0.72 \\
\hline & Larval & 13679 & CYP3 & $6 \mathrm{~B} 2,6 \mathrm{~B} 6,6 \mathrm{~B} 7$ & $\begin{array}{l}89 \%, H . \\
\text { armigera }\end{array}$ & 0.36 \\
\hline & & 22278 & CYP3 & 321B1 & $\begin{array}{l}\text { Spodoptera } \\
\text { litura }\end{array}$ & 1.58 \\
\hline & & 15388 & CYP 3 & $6 \mathrm{AE} 14$ & $\begin{array}{l}100 \%, H \text {. } \\
\text { armigera }\end{array}$ & 19.16 \\
\hline & & 19180 & CYP 3 & $9 \mathrm{~A} 18$ & $\begin{array}{l}74 \%, \mathrm{H} . \\
\text { armigera }\end{array}$ & 7.63 \\
\hline & & 12812 & CYP4 & $4 \mathrm{~L} 6$ & $85 \%$, B. Mori & 1.11 \\
\hline & & 10466 & CYP 4 & 340AA1 & $\begin{array}{l}75 \%, S . \\
\text { littoralis }\end{array}$ & 29.13 \\
\hline & & 10601 & CYP 4 & $341 \mathrm{~A} 2$ & $88 \%$, B. Mori & 3.84 \\
\hline & & 14820 & CYP 4 & 341B1 & $88 \%$, B. mori & 3.57 \\
\hline & Pupa & 28770 & CYP 3 & $9 \mathrm{~A} 14$ & $83 \%$, H. zea & 4.72 \\
\hline & Female & 29309 & CYP 3 & $6 \mathrm{CV} 2$ & $\begin{array}{l}\text { Plutella } \\
\text { xylostella }\end{array}$ & 17.73 \\
\hline & & 29201 & CYP 3 & $6 \mathrm{~B} 1$ & $\begin{array}{l}\text { Papilio } \\
\text { polyxenes }\end{array}$ & 16.33 \\
\hline & & 22936 & CYP 4 & $402 C 1$ & $\begin{array}{l}78 \% \text {, Bemisia } \\
\text { tabaci }\end{array}$ & 14.07 \\
\hline
\end{tabular}

${ }^{\mathrm{a}}$ The cytochrome P450 clan schema used here follows the system proposed by Feyereisen et al. (2006)

${ }^{\mathrm{b}} \mathrm{RPKM}<0.1$ was used as the criterion to judge the unigenes were not expressed during a given developmental stage
P450 are significantly increased by 2-TD treatment: CYP18A1 (unigenes 41217, 35643, 16953), CYP314A1 (unigenes 16487), these up-regulated genes are shown with solid red lines in Fig. 4. The dashed blue and red lines indicate the down- and up-regulated products, respectively, and Fig. 5 shown that $20 \mathrm{E}$ titers in the 2TD treated group were higher than in the control group. The expression of three hormone metabolism related unigenes were not affected by 2-TD treatment (Additional file 9, Fig. 5). The Real-Time qPCR results of the other 2TD-induced $22 \mathrm{P} 450$ unigenes were consistent with the DGE gene expression profiles, suggesting that the DGE results were reliable (Additional file 10).

\section{RNA interference (RNAi) insect hormones-related P450 genes}

CYP307A1 (unigenes 8199, 13311), an insect hormonerelated $\mathrm{P} 450$ gene that was down-regulated by 2-TD in $H$. armigera, was selected for RNAi knockdown studies. The CYP307A1 dsRNA-treated larvae showed significant reduction of CYP307A1 expression as compared to the larvae treated with GFP dsRNA (Fig. 6a). Compared to the control, 90 and $85 \%$ of CYP307A1 expression was suppressed at $12 \mathrm{~h}$ and $24 \mathrm{~h}$ after feeding larvae artificial diet with $35 \mu \mathrm{g} / \mathrm{g}$ (w:w) CYP307A1 dsRNA, respectively. However, no significant retardation of transcription was observed at 36 or $48 \mathrm{~h}$ after feeding (Fig. 6a).

The effect of the RNAi-based knockdown of CYP307A1 on larval survival rates was evaluated in second instar 


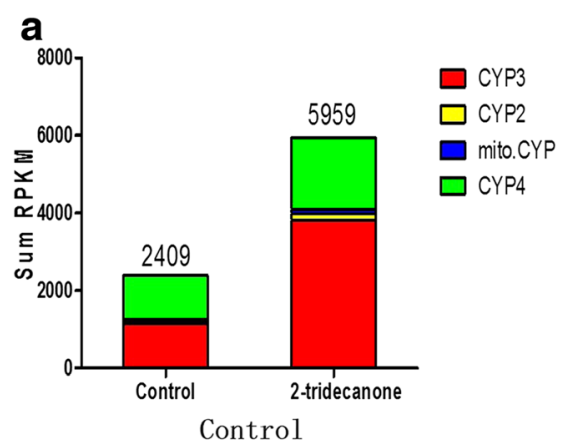

C

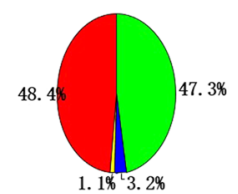

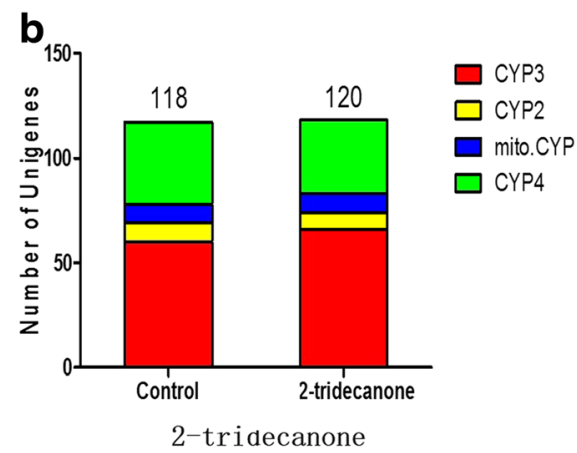

d

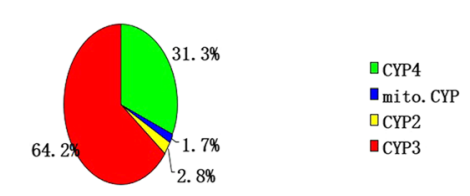

Fig. 4 2-TD affects the expression of P450. a The sum of the expression of P450 unigenes in 2-TD treated and untreated groups. $\mathbf{b}$ Numbers of P450 unigenes in 2-TD treated and untreated groups. c The percentage of each CYP clan expressed in $6^{\text {th }}$ larvae. $\mathbf{d}$ The percentage of each CYP clan expressed in $6^{\text {th }}$ larvae treated with 2-TD. Control: $6^{\text {th }}$ larvae un-treated with 2-TD; 2-tridecanone: $6^{\text {th }}$ larvae treated with 2 -TD for 24 h

larvae by feeding artificial diet mixed with $35 \mu \mathrm{g} / \mathrm{g}$ (w:w) CYP307A1 dsRNA and 2-TD $(0.1 \mathrm{mg} / \mathrm{g})$ for 1,3 , and 5 days. Compared to treated with ds CYP307A1 larvae, the survival rate dramatically decreased in larvae treated the mixture of CYP307A1 with 2-TD. The survival rate was $72 \%$ for the treatment with ds CYP307A1 and $61 \%$ for the mixture of CYP307A1 with 2-TD, through continuous feeding for 5 days (Fig. 6b).

\section{Discussion}

Our experimental results showed that the plant allelochemical 2-TD affects insect development (Table 1), and we observed that a decrease in the concentration of $20 \mathrm{E}$ occurred along with the growth retardation symptoms following 2-TD treatment (Table 1). 2-TD treatment induced the expression of P450 detoxification enzyme genes. Insect $\mathrm{P} 450$ enzymes are classified into four major clans, namely the CYP2, CYP3 (including CYP6 and CYP9), CYP4, and the mito.CYP clan [23]. The mito.CYP, CYP2, and CYP4 clans contain a variety of singlemember CYP families that are known to play important roles in diverse physiological processes [24-31]. The CYP3 clan in insects can be further subdivided into the CYP6 and CYP9 families, which participate primarily in the metabolism of xenobiotic compounds [19, 32].

$20 \mathrm{E}$ is a polyhydroxylated steroid hormone that controls molting and thereby affects the growth of arthropods. Studies using $D$. melanogaster have revealed that the Halloween P450 genes (CYP307A1/A2, CYP306A1, CYP302A1, CYP315A1, and CYP314A1) are essential for each of the steps in $20 \mathrm{E}$ biosynthesis [25, 33, 34]. CYP18A1 belongs to the CYP2 clan and takes part in 20E inactivation, converting $20 \mathrm{E}$ to 20 , 26-dihydroxyecdysone [29]. In B. mori, CYP18A1 not only has temporal- and tissue-specific expression profiles, but also exhibits a distinct expression pattern that closely coincided with the peak of ecdysteroid accumulation in the hemolymph of $B$. mori, a finding that further suggests that orthologous CYP18A1 in insects is closely related to ecdysteroid homeostasis [35]. Interestingly, we also observed that 2TD treatment dramatically increased the expression of CYP18A1 (41217, 35643, 16953) (Table 3, Fig. 5), the increasing CYP18A1 will lead a lower concentration of 20E. Our results clearly show that treatment of larvae with 2-TD decreased 20E concentrations (Table 1) and suppressed larval growth. CYP306A1 (13036), CYP307A1 (8199, 13311), CYP314A1 (16487, 15409), and CYP315A1 (40026) may be also essential for 20E biosynthesis. Treatment with 2-TD decreased the expression levels of these unigenes. We used RNAi methods to confirm the function of CYP307A1 in $H$. armigera. Larvae treated with CYP307A1 dsRNA had dramatically decreased survival rates compared to the GFP dsRNA control, this symptom was similar with RNAi CYP307A1 in D. melanogaster [36]. Compared to treated with ds CYP307A1 larvae, the survival rate dramatically decreased in larvae treated the mixture of CYP307A1 with 2-TD (Fig. 6b), these results proved that the retardant effect of 2-TD is mediated by CYP307A1 on development of cotton bollworm. Some unigenes were annotated as the same P450 gene, but these unigenes have different expression profiles in one sample, these phenomenon maybe caused by these unigenes are not full-length P450 genes or they have allele genes. 
Table 3 Up- and down-regulated P450 genes in cotton bollworm in response to 2-TD treatment

\begin{tabular}{|c|c|c|c|c|c|c|c|}
\hline Family & Classification & $\begin{array}{l}\text { Homologous } \\
\text { genes }\end{array}$ & $\begin{array}{l}\% \text { similarity, } \\
\text { organisms }\end{array}$ & $\begin{array}{l}\text { Transcripts } \\
\text { number }\end{array}$ & $\log _{2}$ Ratio $^{a}$ & Expression stage & 2-TD inducec \\
\hline \multirow[t]{43}{*}{$\mathrm{P} 450 \mathrm{~s}^{\mathrm{b}}$} & \multirow[t]{5}{*}{ Mitochondrial } & $314 A 1$ & $86 \%$, B. mori & 16487 & 2.55 & All, $3>1>6$ & Up \\
\hline & & $314 A 1$ & $83 \%$, S. littoralis & 15409 & -2.29 & All, $3>1>6$ & Down \\
\hline & & 333B3 & $69 \%$, S. littoralis & 12317 & -1.12 & All, $1>6>3$ & Down \\
\hline & & $333 \mathrm{~A} 3$ & $75 \%$, S. littoralis & 25319 & 1.44 & All, $3>1>6$ & Up \\
\hline & & $315 A 1$ & $73 \%$, S. littoralis & 40026 & -1.07 & All, $3>1>6$ & Down \\
\hline & \multirow[t]{7}{*}{ Clan 2} & $18 \mathrm{~A} 1$ & $72 \%$, S. littoralis & 41217 & 4.12 & All, $6=3=1$ & Up \\
\hline & & $18 \mathrm{~A} 1$ & $81 \%$, S. littoralis & 35643 & 5.06 & $3>1$, pupa, female & Up \\
\hline & & $18 \mathrm{~A} 1$ & $76 \%$, S. littoralis & 16953 & 4.73 & $3>1$ & Up \\
\hline & & $15 C$ & $71 \%$, B. mori & 14800 & 1.53 & 1, female & Up \\
\hline & & $306 \mathrm{~A} 1$ & $82 \%$, S. littoralis & 13036 & -3.32 & All, $3>1>6$ & Down \\
\hline & & $307 A 1$ & $99 \%, H$. armigera & 8199 & -4.55 & $3>6>1$, pupa & Down \\
\hline & & 307A1 & $99 \%, H$. armigera & 13311 & -4.92 & Egg, $3>6$, pupa & Down \\
\hline & \multirow[t]{31}{*}{ Clan 3 (include CYP6 and CYP9) } & $6 \mathrm{~B} 2,6 \mathrm{~B} 6,6 \mathrm{~B} 7$ & $96 \%, H$. armigera & 18705 & 3.08 & Egg, female & Up \\
\hline & & $6 \mathrm{~B} 2,6 \mathrm{~B} 6,6 \mathrm{~B} 7$ & $94 \%, H$. armigera & 40306 & 2.23 & All, $3>1>6$ & Up \\
\hline & & $321 \mathrm{~A} 2$ & $98 \%$, H. zea & 17923 & 7.79 & No expression & Up \\
\hline & & $6 B 2$ & $96 \%, H$. armigera & 2844 & 3.03 & All, $6>3>1$ & Up \\
\hline & & $6 \mathrm{~B} 2,6 \mathrm{~B} 6,6 \mathrm{~B} 7$ & $97 \%, H$. armigera & 41374 & 4.08 & $3>1>6$, male & Up \\
\hline & & $6 \mathrm{~B} 31$ & $77 \%$, S. littoralis & 2950 & 1.67 & Male & Up \\
\hline & & $6 \mathrm{AB} 31$ & $74 \%$, S. littoralis & 5881 & 2.39 & $1>3>6$, pupa, Adults & Up \\
\hline & & $6 \mathrm{~B} 6$ & $99 \%, H$. armigera & 39825 & 2.09 & $6>3>1$ & Up \\
\hline & & $6 \mathrm{~B} 2,6 \mathrm{~B} 6,6 \mathrm{~B} 7$ & $89 \%, H$. armigera & 13679 & 4.38 & 3 & Up \\
\hline & & 6AN4 & $72 \%$, S. littoralis & 12093 & 1.96 & Egg,female,1 > $3>6$ & Up \\
\hline & & 6AN4 & $78 \%$, S. littoralis & 1833 & 1.07 & $1<3<6$ & Up \\
\hline & & $6 \mathrm{AB4}$ & $74 \%$, B. mori & 42286 & 5.24 & Male & Up \\
\hline & & $6 \mathrm{AB} 14$ & $68 \%$, S. littoralis & 15424 & -1.39 & $3>6$ & Down \\
\hline & & $6 \mathrm{AE} 12$ & $72 \%, H$. armigera & 41540 & 2.64 & Female, male & Up \\
\hline & & $6 \mathrm{AE} 12$ & $90 \%, H$. armigera & 3564 & 2.35 & $3>6>1$, female & Up \\
\hline & & $6 \mathrm{AE} 14$ & $99 \%, H$. armigera & 9094 & -1.55 & $1>3>6$ & Down \\
\hline & & 6AE14 & $78 \%, H$. armigera & 4567 & 1.68 & $1>3>6$, female, male & Up \\
\hline & & $6 \mathrm{AE} 14$ & $100 \%$, H. armigera & 15388 & 1.97 & All & Up \\
\hline & & $6 \mathrm{AE} 14$ & $92 \%, H$. armigera & 6041 & 1.16 & $3>6>1$ & Up \\
\hline & & $6 \mathrm{AE} 47$ & $75 \%$, S. littoralis & 39097 & 2.37 & $6>1>3$, female & Up \\
\hline & & $6 \mathrm{AE} 14$ & $72 \%, H$. armigera & 30146 & 3.25 & egg, $3>1>6$, female & Up \\
\hline & & $324 A 6$ & $72 \%$, S. littoralis & 40289 & 2.84 & 3, pupa & Up \\
\hline & & 337B3 & $99 \%, H$. armigera & 2773 & 2.64 & Egg, female & Up \\
\hline & & 337B3v1 & $85 \%, H$. armigera & 12899 & 1.29 & All, $3>6>1$ & Up \\
\hline & & $35 \mathrm{D} 18$ & $97 \%, H$. armigera & 17285 & -3.63 & $6>3>1$ & Down \\
\hline & & $35 D 18$ & $91 \%, H$. armigera & 11744 & -4.67 & $6>3>1$ & Down \\
\hline & & $324 \mathrm{~A} 1$ & $77 \%$, S. littoralis & 36658 & 2.03 & Female, male & Up \\
\hline & & $321 \mathrm{~A} 1$ & $96 \%$, H. zea & 38041 & 4.82 & Egg, $1<3<6$ & Up \\
\hline & & $321 \mathrm{~A} 1$ & $95 \%$, H. zea & 6465 & 6.56 & $3>6>1$, male & Up \\
\hline & & $321 \mathrm{~A} 2$ & $91 \%$, H. zea & 9454 & 2.62 & Egg, female & Up \\
\hline & & $321 \mathrm{~A} 2$ & $89 \%$, H. zea & 2372 & 1.53 & Egg, pupa, female & Up \\
\hline
\end{tabular}


Table 3 Up- and down-regulated P450 genes in cotton bollworm in response to 2-TD treatment (Continued)

\begin{tabular}{|c|c|c|c|c|c|c|}
\hline & $321 \mathrm{~B} 1$ & $90 \%$, S. littoralis & 40435 & 1.84 & egg, female & Up \\
\hline & $9 A 18$ & $88 \%, H$. armigera & 35600 & -3.47 & $6>1>3$, pupa & Down \\
\hline & $9 \mathrm{~A} 18$ & $99 \%, H$. armigera & 40298 & -3.49 & All, $6>3>1$ & Down \\
\hline & $9 A 18$ & $99 \%, H$. armigera & 6517 & -4.46 & $6>1>3$ & Down \\
\hline & $9 A 12$ & $96 \%, H$. armigera & 16315 & 1.511 & $3>1>6$, female, male & Up \\
\hline & 9A14 & $94 \%$, H. zea & 13079 & 1.65 & Egg, female & Up \\
\hline & $337 \mathrm{~B} 3 \mathrm{v} 7$ & $96 \%$, H. zea & 33786 & 1.50 & Egg, female, $3>1>6$ & Up \\
\hline & $321 \mathrm{~A} 2$ & $92 \%$, H. zea & 12163 & 7.21 & $6>3>1$, male & Up \\
\hline \multirow[t]{20}{*}{ CYP4 } & $4 \mathrm{~V} 2$ & $88 \%$, Mamestra brassicae & 17185 & 2.32 & All, $3>1>6$ & Up \\
\hline & $340 \mathrm{~K} 4$ & $69 \%$, S. littoralis & 8795 & -1.95 & $3>1>6$ & Down \\
\hline & $4 \mathrm{M7}$ & $96 \%$, H. zea & 32914 & 3.18 & $3>6>1$, pupa & Up \\
\hline & $4 \mathrm{M} 7$ & $97 \%$, H. zea & 34657 & 1.79 & $3>6>1$, pupa & Up \\
\hline & $4 \mathrm{~L} 12$ & $74 \%$, S. littoralis & 41937 & 5.61 & All, $1>3>6$ & Up \\
\hline & $340 A A 1$ & $66 \%$, S. littoralis & 18087 & 2.03 & Egg, 3 & Up \\
\hline & $340 A A 1$ & $70 \%$, S. littoralis & 23572 & 1.03 & 3 , male & Up \\
\hline & 4M14V1 & 76\%, S. litura & 22567 & 1.50 & Pupa & Up \\
\hline & $4 \mathrm{C} 1$ & $71 \%$, Blaberus discoidalis & 26692 & 1.77 & All & Up \\
\hline & $4 \mathrm{~S} 1$ & $96 \%, H$. armigera & 1070 & -1.29 & $6>1>3$,female,pupa & Down \\
\hline & $367 B 6$ & $73 \%$, S. littoralis & 15813 & 2.03 & 3, pupa, female & Up \\
\hline & $340 A A 1$ & $70 \%$, S. littoralis & 21273 & 2.03 & 3 & Up \\
\hline & $4 \mathrm{G} 74$ & $83 \%$, S. littoralis & 4194 & -1.91 & $3>6>1$,pupa, female & Down \\
\hline & $4 \mathrm{G} 15$ & D. melanogaster & 2239 & -3.21 & $1=3<6$, female & Down \\
\hline & $4 \mathrm{G} 74$ & $86 \%$, S. littoralis & 14395 & -3.56 & $3>6>1$, pupa, female & Down \\
\hline & 341B1 & $76 \%$, B. mori & 3370 & -1.92 & $6>3>1$ & Down \\
\hline & 341B1 & $67 \%$, B. mori & 40986 & -1.19 & Pupa & Down \\
\hline & $341 B 3$ & $78 \%$, S. littoralis & 7936 & -1.14 & $6>3>1$ & Down \\
\hline & $341 \mathrm{~A} 13$ & $83 \%$, S. littoralis & 26038 & -1.55 & 3 , female & Up \\
\hline & $4 \mathrm{Cl}$ & $88 \%$, B. mori & 22272 & -2.43 & 6 & Down \\
\hline
\end{tabular}

${ }^{a}$ Ratio: RPKM of 2-TD treated samples/RPKM of untreated samples. RPKM: Reads per kilo bases per million reads. RPKM $<0.1$ was used as the criterion to judge the unigenes were not expressed during a given developmental stage. Absolute value of $\log _{2}$ Ratio $\geq 1$ were used as thresholds for 'differential expression'. The P450 genes reported to be involved in insect hormone biosynthesis and metabolism are shown in bold. 1: $1^{\text {st }}$ instar larvae; $3: 3^{\text {rd }}$ instar larvae; 6 : $6^{\text {th }}$ instar larvae

${ }^{\mathrm{b}}$ The cytochrome P450 clan schema used here follows the system proposed by Feyereisen et al. (2006)

CYP15A1 encodes an enzyme that catalyzes the last step in $\mathrm{JH}$ biosynthesis, catalyzing the epoxidation of methyl farnesoate into JH III in D. punctate [37]. CYP4C7, expressed in a heterologous system, was able to metabolize $\mathrm{JH}$ III and $\mathrm{JH}$ precursors into 12transhydroxy [30]. Although CYP4C7 and CYP15A1 were not found to be regulated by $2-\mathrm{TD}$, the percentage of expressed CYP4 genes decreased following 2-TD treatment in $H$. armigera (Table 3 ), and the percentage of expressed CYP4 unigenes suddenly increased during the transformation from eggs to larvae; the percentage of expressed CYP4 decreased during the transformation from larvae to pupae (Fig. 1). 48 P450 unigenes of the CYP4 clan were found in our study. CYP4C15, initially cloned from the steroidogenic glands (Y-organs) of crayfish, has been suggested to be involved in ecdysteroid biosynthesis [38]. In Diploptera punctata, CYP4C7 is expressed selectively in the corpora allata and metabolizes $\mathrm{JH}$ and its precursors into new metabolites [10, 30]. CYP4 unigenes in H. armigera homologous to CYP15A1 and CYP4C7 may be involved in $\mathrm{JH}$ biosynthesis and metabolism. In our study, the expression of these genes in larvae was higher than in eggs, and was induced by 2 TD treatment (Table 3). Four CYP4 unigenes (12812, $10466,10601,14820$ ) were specifically expressed in larvae, and one CYP4 unigene (22936) was solely expressed in females. These expressed P450 unigenes seem likely to play important roles during these specific stages (Table 1). 2-TD treatment strongly induced the expression of CYP4 unigenes in $6^{\text {th }}$ instar larvae (Fig. 4a), a finding consistent with previous research in other insects [23]. These imply that the increased expression of 


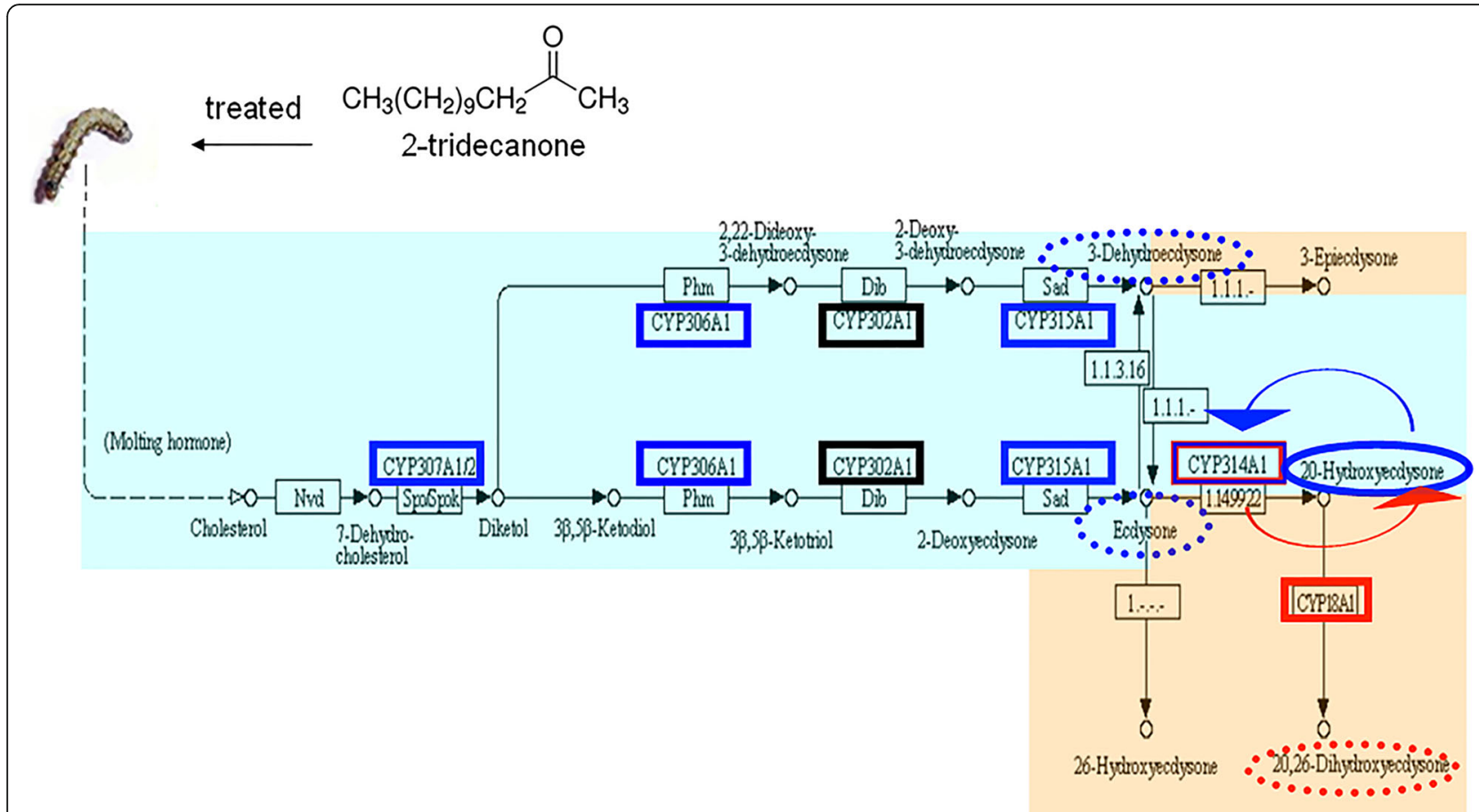

Fig. 5 2-TD affects the biosynthesis and metabolism of insect hormones ( $\mathrm{JH}$ and molting hormone). Genes down-regulated following treatment with 2-TD are shown with solid blue lines, up-regulated genes are shown with solid red lines. The dashed blue and red lines indicate the down- and up-regulated products, respectively. The portion with a blue background shows the biosynthetic pathway of 20E; portions with red backgrounds show the metabolic pathways of insect hormones [25, 29, 33, 34]

CYP4 transcripts induced by 2-TD treatment would likely also affect JH biosynthesis and metabolism.

Our DGE analysis found that CYP333B3 (12317) and CYP333A3 (25319), which belong to the mito.CYP clan, were also regulated by 2-TD (Table 3). Other 2-TDregulated mito.CYP genes are related to the metabolism of molting hormone, but there have been no reports to prove that these two unigenes are involved in the biosynthesis or metabolism of molting hormone. Both the up- and down-regulation of these two P450 unigenes may be of critical importance in the development and metamorphosis of insects. As many of these genes are conserved among many insect species, our study provides a foundation for the functional characterization of the roles of these two P450 unigenes in insect development and metamorphosis.

About 80 P450 unigenes of the CYP3 clan were identified in our study. Within the genus Papilio (Lepidoptera: Papilionidae), CYP6 family members are known to detoxify furanocoumarins, secondary metabolites characteristic of the host plant families consumed by these insects [14, 39-45]. In our study, four P450 unigenes (13679, 22278, 15388, 19180) shared homology with CYP6B2, CYP321B1, CYP6AE14, and CYP9A18. These unigenes all belong to the CYP3 clan are known to be specifically expressed in larvae, and are thought to
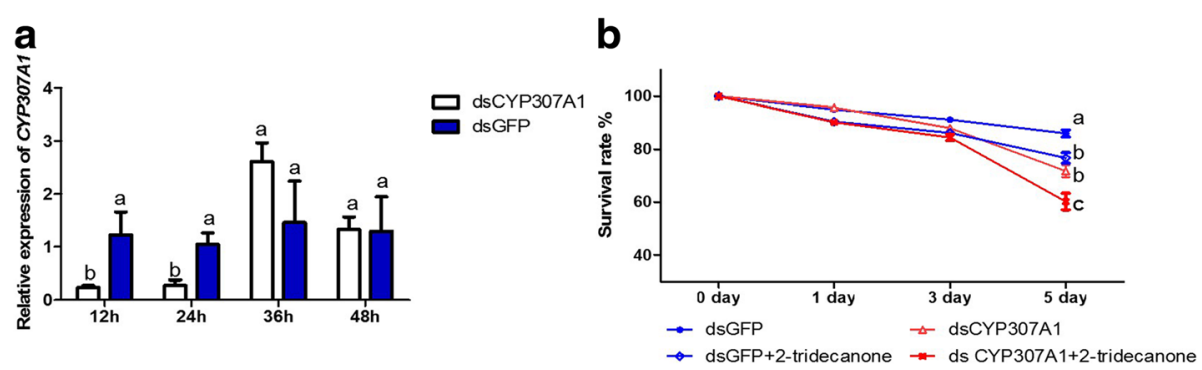

Fig. 6 CYP307A1 RNAi. a The dsRNA-mediated depletion of CYP307A1 transcripts in larvae fed with CYP307A1 dsRNA. b RNAi CYP307A1 effects on the development of H.armigera. Second-instar larvae were fed on a diet containing $5 \mu \mathrm{g} / \mathrm{g}$ or $35 \mu \mathrm{g} / \mathrm{g}$ (w:W) dsRNA, and samples were collected at $12,24,36$, and $48 \mathrm{~h}$ after feeding. GFP dsRNA was used as a control, at the same concentrations. In the each diagram, bars sharing the same letter for each time point group are not significantly different at the $P>0.05$ level 
participate primarily in the metabolism of plant allelochemicals $[12,14]$. Two CYP3 unigenes were expressed only in adult females. One CYP3 unigene was specifically expressed in egg and pupa, respectively (Table 2). The ability of insects to metabolize xenobiotic compounds at different development stages may be related to these CYP3 clan P450 unigenes.

\section{Conclusions}

In conclusion, we found that 2-TD can retard the development of cotton bollworm, and a decrease of the concentration of $20 \mathrm{E}$ occurred alongside the retardant symptoms (Table 1). In order to further illuminate the relationship between 2-TD and its function in retarding the development of insects, the transcriptome of $H$. armigera was sequenced and digital gene expression libraries were constructed in the present study. The expression of CYP314A1, CYP315A1, CYP18A1, CYP307A1, and CYP306A1 was found to be induced by 2-TD, and these genes were also related to the biosynthesis or metabolism of 20E. Expression analysis and RNAi studies proved that the retardant effect of 2-TD is mediated by P450 genes on development of cotton bollworm.

\section{Methods}

\section{Insect samples}

The cotton bollworm population used in this study (a laboratory population) was initially collected from the Handan region of Hebei Province, China, in 1998, and reared on an artificial diet in a growth room maintained at $26 \pm 1{ }^{\circ} \mathrm{C}, 70-80 \%$ relative humidity, with a photoperiod of 16:8 (L:D). The population was never exposed to any pesticides. The composition of the artificial diet was as follows: corn flour $300 \mathrm{~g}$, soybean powder $100 \mathrm{~g}$, yeast extract powder $100 \mathrm{~g}$, citric acid $2.5 \mathrm{~g}$, vitamin $\mathrm{C}$ $10 \mathrm{~g}$, sorbic acid $1.5 \mathrm{~g}$, vitamin B $1.5 \mathrm{~g}$, erythromycin $0.05 \mathrm{~g}$, propionic acid $5 \mathrm{~mL}$, vitamin $\mathrm{E} 1.5 \mathrm{~g}$, water $2.5 \mathrm{~L}$. Adults were held under the same conditions and supplied with a $10 \%$ sugar solution. Females were induced to oviposit into gauze. Eggs were collected from this gauze. All specimens at all life stages were pesticide-free and were reared in a growth chamber set to the aforementioned environmental conditions. The newly molted $6^{\text {th }}$ instar larvae, after molted for 1 day, were treated by $12 \mathrm{~h}$ of starvation treatment, then the larvae were exposed to the artificial diet mixed with 2TD (Sigma-Aldrich, MO, USA) (99\% purity) $10 \mathrm{mg} / \mathrm{g}$ (w:w) for $24 \mathrm{~h}$ (ethyl alcohol as negative control). Each treatment contained twenty five larvae, and these experiments were repeated four times.

\section{Quantification of Ecdysteroids}

Total 20Ewere quantified by enzyme immunoassay (EIA). Newly molted sixth instar larvae treated with 2-TD (twenty five larvae/tube with four replicates) were homogenized and extracted as described previously [46]. The extracts were evaporated, redissolved, and subjected to ecdysteroid enzyme-linked immunosorbent assay (ELISA). The ELISA was performed in a competitive assay format using anti-20E rabbit antiserum (Cayman Chemical, Michigan, USA), acetylcholinesterase-conjugated 20E (Cayman Chemical, Michigan, USA), and standard 20E (Sigma-Aldrich, St. Louis, MO, USA). The acetylcholinesterase activity was quantified by Ellman's Reagent (Cayman Chemical, Michigan, USA), and the absorbance at $415 \mathrm{~nm}$ was detected with a Benchmark microplate reader (Bio-Rad Laboratories, Hercules, USA).

\section{RNA isolation}

Total RNA was isolated from specimens at the following developmental stages: eggs collected within $24 \mathrm{~h}$ of postoviposition; first-instar larvae; third-instar larvae; sixthinstar larvae not treated with 2-tridecane; pupae; mating adults (females and males, within 6 days of eclosion); and sixth-instar larvae treated with 2-TD. For each sample, approximately $800 \mathrm{mg}$ of insect material was homogenized with liquid nitrogen in a mortar in order to reduce the effect of error. RNA was extracted using an RNeasy plus Micro Kit (Qiagen GmbH, Germany) following the manufacturer's instructions. RNA was quantified by measuring the absorbance at $260 \mathrm{~nm}$ using a NanoDrop 1000 A spectrophotometer (GE Healthcare, Uppsala, Sweden). The purity of all RNA samples was assessed at an absorbance ratio of $\mathrm{OD}_{260 / 280}$ and $\mathrm{OD}$ 260/230, and the integrity of RNA was confirmed by electrophoresis on $1 \%$ agarose gels.

\section{Construction of the CDNA library and Illumina sequencing for transcriptome analysis}

Briefly, $12 \mathrm{mg}$ total RNA (a mixture of RNA from eggs, $1^{\text {st }}$ instar larvae, $3^{\text {rd }}$ instar larvae, $6^{\text {th }}$ instar larvae, pupae, adult females and males, all at equal proportions) was used to construct a cDNA library of transcriptome. Poly (A) mRNA was purified from total RNA using oligo (dT) magnetic beads. These short fragments were then used as templates for the synthesis of first-strand cDNA. Second-strand cDNA was synthesized using DNA polymerase I, and the samples were treated with RNaseH. Short fragments were purified using a QiaQuick PCR extraction kit (Qiagen GmbH, Hilden, Germany). These fragments were subsequently washed with elution buffer for end reparation poly (A) addition and then ligated to sequencing adapters. Suitable fragments, as determined by agarose gel electrophoresis, were selected for use as templates for PCR amplification. The cDNA library was sequenced using the Illumina Solexa platform. 
Assembly and functional annotation of the transcriptome Using Trinity program to assembly transcripts, all of the raw sequences were filtered to remove low quality and adaptor sequences [47]. Open reading frame (ORF) of the unigenes were predicted using the ORF finder tool (https://www.ncbi.nlm.nih.gov/orffinder/). All unigenes were queried against the NCBI $\mathrm{Nr}$ protein database with an e-value cutoff of $1 \mathrm{e}^{-5}$ for functional annotation. The BLASTN algorithm was also used to query the unigenes against the NCBI Nt nucleotide databases $\left(\mathrm{Nt}\right.$; e-value $<10^{-5}$ ). For quantitative assessment of the assembly and annotation completeness, in comparison with the arthropod profile in OrthoDB v8 [48], we applied the software tool BUSCO [49], which is based on evolutionarily informed expectations of gene content, with default settings. Then, the BLAST results were used to do a tentative functional annotation of the unigenes with GO, KEGG and COG databases (e-value < $10^{-5}$ ). The clean reads and computationally assembled sequences from this study were submitted to the Sequence Read Archive (SRA) database (Accession number: SRX374716).

\section{Selection of cytochrome P450 sequences and phylogenetic analysis}

Sequences encoding genes related to cytochrome P450s were identified by BLASTX analysis against the NCBI nr database, with a cut-off value of e-value $<10^{-5}$. Sequences that returned redundant BLASTX results, or those that showed high homology with each other as determined by the alignment results, were eliminated as likely allelic variants or different portions of the same gene. MEGA 6.0 software was used to analyze the phylogenetic relationships between the P450 unigenes of $H$. armigera and the published P450 sequences from Bombyx mori (B. mori). The amino acid sequences for each predicted protein were aligned using MAFFT 7.110 [50]. Neighborjoining trees were produced using MEGA 6.0 with Poisson correction of distances [51], and 1000 neighbor-joining bootstrap replicates.

\section{Preparation and sequencing of the DGE library}

RNA was extracted separately from eggs, $1^{\text {st }}$ instar larvae, $3^{\text {rd }}$ instar larvae, $6^{\text {th }}$ instar larvae, pupae, adults (females and males), and sixth-instar larvae treated with 2-TD. The extractions were performed using an RNeasy plus Micro kit (Qiagen GmbH, Hilden, Germany) according to the manufacturer's instructions. Approximately $10 \mu \mathrm{g}$ RNA from each sample was used for the construction of DGE libraries. mRNA was treated as described in the cDNA library construction methods, above. The fragments were purified by agarose gel electrophoresis and enriched by PCR amplification. The library products were then sequenced with the Illumina Solexa platform. The raw data (tag sequences and counts) were deposited in the NCBI SRA database, under accession number: SRX684363.

\section{Bioinformatics pipeline and analysis of DGE libraries}

Sequencing raw data were transformed by base calling into raw sequence data. Clean tags were obtained after the raw sequences were filtered to remove adaptor sequences, empty tags, low quality tags, tags that were too short $(<200 \mathrm{bp})$, and tags with a copy number of 1 . All clean tags were mapped to the transcriptome of $H$. armigera with a stringency allowing no more than $1 \mathrm{nu}$ cleotide mismatch. The number of unambiguous, clean tags for each gene was calculated, and then normalized to RPKM (Reads Per Kilo bases per Million reads), using the following equation: $\frac{R P K M=10^{6} / \mathrm{C}}{N L / 10^{3}}$ in which $C$ is the number of reads uniquely mapped to a given gene, $N$ is the number of reads uniquely mapped to all genes, and $L$ is the total length of the exons in the given gene. For genes with more than one alternative transcript, the longest transcript was selected to calculate the RPKM. The RPKM method eliminates the influences of different gene lengths and sequencing discrepancies on gene expression calculations. Therefore, RPKM values can be used directly for comparing differences in gene expression among samples. [52]. RPKM $<0.1$ was used as the criterion to judge if a given unigene was not expressed in one specimen.

For gene expression profiling analysis, unigenes were assigned GO terms using the Blast2GO and canonical pathways tools of the KEGG pathway enrichment analysis. Analysis of the differentially expressed genes was performed based on the GOstat algorithm [53]. To identify the differentially expressed genes among different development libraries (egg, $1^{\text {st }}$ instar larvae, $3^{\text {rd }}$ instar larvae, $6^{\text {th }}$ instar larvae, pupae, adult females and males libraries), each library compared with egg library, and the fold change $\log _{2}$ Ratio $\geq 1$ values were used as threshold criteria to judge the differences in gene expression [54]. Compared with $6^{\text {th }}$ instar larvae library, the differentially expressed genes among $6^{\text {th }}$ instar larvae library and 2-TD treated library were also identified by $\log _{2}$ Ratio $\geq 1$ values. The percentage of each CYP clan (mitochondrial, clan 2, clan3 and clan4) expressed in each DGE library was calculated according to the following formula: (Sum RPKM of each CYP clan)/ $($ Sum RPKM of P450) $\times 100 \%$.

\section{Validation of P450 gene expression profiles by Real-Time PCR}

To confirm the gene expression profile results from the DGE libraries, the expression of $35 \mathrm{P} 450$ unigenes (including 12 hormone-related $\mathrm{P} 450$ unigenes) were analyzed with Real-Time qPCR. Specific primers were 
designed using Primer 5.0 software, and are listed in Additional file 12. EF- $\alpha$ was used as an internal control. Three biological replicates were performed for qPCR assay. The efficiency of each set primer was about $100 \%$ (Additional file 12). RNA isolation was performed using TRIzol reagent, according to the manufacturer's instructions (Invitrogen, Carlsbad, CA, USA). Samples were treated with RNase-free DNase I (Takara Biotechnology Dalian Co., Ltd., Dalian, China). First-strand cDNA synthesis was performed with $1 \mu \mathrm{g}$ of total RNA by using a Transcriptor First Strand cDNA Synthesis Kit (Takara Biotechnology Dalian Co., Ltd., Dalian, China). cDNA was amplified using an Applied Biosystems7500 qPCR System (Applied Biosystems, Foster City, USA) with a Real Master Mix SYBR Green PCR kit (Invitrogen Carlsbad, CA, USA). Amplification conditions consisted of an initial pre-incubation at $95^{\circ} \mathrm{C}$ for $5 \mathrm{~min}$, followed by amplification of the target DNA for 40 cycles of $94{ }^{\circ} \mathrm{C}$ for $30 \mathrm{~s}, 60{ }^{\circ} \mathrm{C}$ for $30 \mathrm{~s}, 72{ }^{\circ} \mathrm{C}$ for $30 \mathrm{~s}$ and $95^{\circ} \mathrm{C}$ for $5 \mathrm{~min}$. The melting curves of the amplicons were measured by taking continuous fluorescence readings whilst increasing the temperature from 58 to $95{ }^{\circ} \mathrm{C}$, with $0.5{ }^{\circ} \mathrm{C}$ incremental increases every 10 s. geNorm version 3.5 [55] and Normfinder version 0.953 [56] software were used to evaluated the raw CT values of the selected reference genes as described in their manuals. Candidate gene with the lowest $M$ value should be the most stably expressed reference gene, and EF-1a was chose as the reference gene (Additional file 13). For each gene, a standard curve was generated for each set of primers, and the efficiency of each reaction was determined.

Statistical analyses of Real-Time qPCR results were performed using GraphPad Prism 5.0 software (GraphPad prism, Prism 5 for Windows). Statistical significance was determined by using a Student's t-test, and a $\mathrm{p}$ value less than 0.05 was considered to indicate statistical significance.

\section{RNAi insect hormone-related P450 genes}

Based on the CYP307A1 gene sequence (Gene bank number: KM016704.1) and predicted possible interference sites obtained using online prediction software (http://www.dkfz.de/signaling/e-rnai3/), we designed specific primers using DNAMAN 6.0 software. A 494-bp fragment of CYP307A1 (position 730-1310) was amplified and cloned into the pMD-18simple-T vector (Takara, Dalian, China), using the dsRNAi-CYP307A1-1 and dsRNAi-CYP307A2-2 primer pair (Additional file 12), which contained additional T7 promoter sequences. Purified plasmids served as templates for RNA synthesis using a MEGAscript T7 transcription kit (Ambion, Austin, TX, USA). GFP dsRNA, which was used as the control, was synthesized with the same procedures as above, using the dsGFP-F and dsGFP-R primers
(Additional file 12). dsRNA from GFP and CYP307A1 were derived by using the MEGAscript T7 transcription kit with an extended transcription time of $5 \mathrm{~h}$ at $37{ }^{\circ} \mathrm{C}$. The resulting dsRNA was digested by DNase I and RNase to remove DNA and any single-stranded RNA, and finally dissolved in DEPC water.

Second-instar larvae, after being starved for $12 \mathrm{~h}$, were exposed to artificial diet containing CYP307A1 dsRNA $(15 \mu \mathrm{g} / \mathrm{g}$ or $35 \mu \mathrm{g} / \mathrm{g}, \mathrm{w} / \mathrm{w})$ mix or not mix with 2-TD $(0.1 \mathrm{mg} / \mathrm{g}$, w/w) for 12,24 , and $36 \mathrm{~h}$; GFP dsRNA was used as a control. Thirty larvae were used in each treatment, and three replications were performed. The dsRNAmediated depletion of CYP307A1 transcripts was experimentally evaluated with qPCR by using the qCYP307A1 -F and $\mathrm{q} C Y P 307 A 1-\mathrm{R}$ primers (Additional file 12).

\section{Additional files}

\section{Additional file 1: Figure $6^{\text {th }}$ instar larvae treated with 2-TD $(10 \mathrm{mg} / \mathrm{g})$. (PDF 170 kb)}

Additional file 2: Output statistics of sequencing and assembly quality for the transcriptomes of $\mathrm{H}$. armigera. (DOCX $13 \mathrm{~kb}$ )

Additional file 3: Species distribution of the BLASTX results. This figure shows the species distribution of unigene BLASTX matches against the $\mathrm{nr}$ protein database (cutoff value e $<10^{-5}$ ). (PDF $214 \mathrm{~kb}$ )

Additional file 4: BUSCO analysis results. (XLSX $79 \mathrm{~kb}$ )

Additional file 5: COG function classification of consensus for the transcriptome of $\mathrm{H}$. armigera. (PDF $68 \mathrm{~kb}$ )

Additional file 6: Classification of the gene ontology (GO) for the transcriptome of $\mathrm{H}$. armigera. Transcripts were annotated in three categories: cellular components, molecular function and biological processes. (PDF $81 \mathrm{~kb}$ )

Additional file 7: Unrooted distance neighbor-joining tree of P450 sequences from H. armigera (Red) and B. mori (Black). Homology with greater than $70 \%$ support with 1000 bootstrap replications is indicated at the corresponding nodes. Branches in different colors show different clans (the mito.CYP clan is shown in red, CYP2 in green, CYP3 in yellow, and CYP4 in blue). (PDF $326 \mathrm{~kb}$ )

Additional file 8: Comparison of the number of digital tags generated from the different stages of $\mathrm{H}$. armigera. (DOCX $14 \mathrm{~kb}$ )

Additional file 9: Validation of hormone-regulated $\mathrm{P} 450$ genes expression by Real Time GPCR. (A) hormone-regulated P450 genes which were downregulated by 2-TD. (B) hormone-regulated $\mathrm{P} 450$ genes which were upregulated by 2-TD. (C) hormone-regulated P450 genes which were not significant inducible by 2-TD. (PDF 398 kb)

Additional file 10: Validation of gene expression by RT-PCR. (A) P450 unigenes which were regulated by 2-TD. (B) P450 unigenes which were not significantly induced by 2-TD. (C) P450 unigenes expressed at specific Developmental stages. (PDF 563 kb)

Additional file 11: The expression of the 153 P450 unigenes in different DGE library. (XLSX 25 kb)

Additional file 12: Primers were used in this manuscript. (DOCX $18 \mathrm{~kb})$

Additional file 13: Expression stability of the candidate reference genes under different conditions. (DOCX $13 \mathrm{~kb}$ )

\section{Abbreviations}

2-TD: 2-Tridecanone; BLASTX: Similarity search of the NCBI protein database using a translated nucleotide query; COG: Clusters of orthologous groups; DGE: Digital gene expression; EIA: Enzyme immunoassay; ELISA: Enzymelinked immunosorbent assay; GO: Gene ontology; JH: Juvenile hormone; KEGG: Kyoto Encyclopedia of Genes and Genomes; nr: NCBI non-redundant 
protein sequences database; nt: NCBI nucleotide collection; ORF: Open reading frame; RNAi: RNA interference; RPKM: Reads Per Kilo bases per Million reads; SRA: Sequence Read Archive

\section{Acknowledgments}

This work was supported by The National Natural Science Foundation of China (No. 31173887) and the National Basic Research and Development Program of China (2012CB114103).

\section{Funding}

Not applicable.

\section{Availability of data and materials}

The transcriptome clean reads and computationally assembled sequences from this study were submitted to the NCBI/SRA database, under accession number: SRX374716. The DGE raw data (tag sequences and counts) were deposited in the NCBI/SRA database, under accession number: SRX684363.

\section{Authors' contributions}

Conceived and designed the experiments: LZ and XG. Performed the experiments: LZ, YL and MX. Analyzed the data: $L Z$ and $Y L$. Contributed reagents/materials/analysis tools: $L Z, Y L, Q S, X G$ and $M X$. Wrote the paper: $L Z$ and $X G$. Bioinformatic analysis: $L Z$ and $Y L$. All authors read and approved the final manuscript.

\section{Competing interest}

The authors declare that they have no competing interests.

\section{Consent for publication}

Not applicable.

\section{Ethics approval and consent to participate}

Not applicable.

\section{Author details}

${ }^{1}$ Department of Entomology, China Agricultural University, Beijing 100193, People's Republic of China. ${ }^{2}$ College of Plant Science and Technology, Jilin University, Changchun 130062, People's Republic of China.

Received: 7 June 2016 Accepted: 9 November 2016

\section{Published online: 22 November 2016}

\section{References}

1. Becerra JX. Insects on plants: Macroevolutionary chemical trends in host use. Science. 1997;276:253-6. View Article: http://science.sciencemag.org/ content/276/5310/253.long PubMed: http://www.ncbi.nlm.nih.gov/ pubmed/?term $=9092474$.

2. Jensen NB, Zagrobelny M, Hjernø K, Olsen CE, Houghton-Larsen J, Borch J, et al. Convergent evolution in biosynthesis of cyanogenic defence compounds in plants and insects. Nat Commun. 2011;2:273. View Article: http://www.nature.com/ncomms/journal/v2/n4/full/ncomms1271.html PubMed: http://www.ncbi.nlm.nih.gov/pubmed/?term = 21505429 .

3. Howe GA, Jander G. Plant immunity to insect herbivores. Annu Rev Plant Biol. 2008;59:41-66. View Article: http://www.annualreviews.org/doi/full/10 1146/annurev.arplant.59.032607.092825? url_ver $=$ Z39.88-2003\&rfr_id = ori\%3Arid\%3Acrossref.org\&rfr_dat =cr_pub\%3Dpubmed\& PubMed: http:// www.ncbi.n/m.nih.gov/pubmed/?term = 18031220 .

4. Despre's L, David JP, Gallet C. The evolutionary ecology of insect resistance to plant chemicals. Trends Ecol Evol. 2007:22(6):298-307. View Article: http:// www.sciencedirect.com/science/article/pii/S0169534707000651 PubMed: http://www.ncbi.nlm.nih.gov/pubmed/?term = 17324485 .

5. Gonçalves MIF, Maluf WR, Gomes LAA, Barbosa LV. Variation of $2-$ Tridecanone level in tomato plant leaflets and resistance to two mite species (Tetranychus sp.). Euphytica. 1998;104(1):33-8. View Article: http:// link.springer.com/article/10.1023/A:1018611514287.

6. Celorio-Mancera MDLP, Wheat CW, Vogel $H$, Soderlind $L$, Janz N, Nylin S. Mechanisms of macroevolution: poly-phagous plasticity in butterfly larvae revealed by RNA-Seq. Mol Ecol. 2013;22:4884-95. View Article: http://onlinelibrary.wiley.com/doi/10.1111/mec.12440/abstract PubMed: http://www.ncbi.nlm.nih.gov/pubmed/?term = 23952264\%5Buid\%5D\&cmd = DetailsSearch
7. Huang W, Siemann E, Xiao L, Yang XF, Ding JQ. Species-specific defence responses facilitate conspecifics and inhibit heterospecifics in above-belowground herbivore interactions. Nat Commun. 2014;5:4851. View Article: http://www.nature.com/ncomms/2014/140922/ ncomms5851/full/ncomms5851.html PubMed: http://www.ncbi.nlm.nih gov/pubmed/?term $=25241651$.

8. Stamp N. Out of the quagmire of plant defense hypotheses. Q Rev Biol. 2003; 78(1):23-55. PubMedhttp://www.ncbi.nlm.nih.gov/pubmed/?term = 12661508 .

9. Kennedy GG. 2-tridecanone, tomatoes and Heliothis zea: potential incompatibility of plant antibiosis with insecticidal control. Ent Exp Appl. 1984;35:305-11. View Article: http://onlinelibrary.wiley.com/doi/10.1111/j. 1570-7458.1984.tb03396.x/citedby.

10. Yu SJ. Allelochemical stimulation of ecdysone 20-monooxygenase in fall armyworm larvae. Arch Insect Biochem. 1995;28(4):365-75. View Article: http://onlinelibrary.wiley.com/doi/10.1002/arch.940280406/abstract.

11. Schuler MA. P450s in plant-insect interactions. Biochim Biophys Acta. 2011;1814(1):36-45. View Article: http://www.sciencedirect.com/science/ article/pii/S157096391000261X PubMed: http://www.ncbi.nlm.nih.gov/ pubmed/?term $=20883828$.

12. Mao YB, Cai WJ, Wang JW, Hong GJ, Tao XY, Wang LJ, et al. Silencing a cotton bollworm P450 monooxygenase gene by plant-mediated RNAi impairs larval tolerance of gossypol. Nat Biotechnol. 2007;25(11):1307-13. View Article: http://www.nature.com/nbt/journal/v25/n11/full/nbt1352.html PubMed: http://www.ncbi.nlm.nih.gov/pubmed/?term = 17982444 .

13. Celorio-Mancera MDLP, Heckel DG, Vogel H. Transcriptional analysis of physiological pathways in a generalistherbivore: responses to different host plants and plant structures by the cotton bollworm, Helicoverpa armigera. Entomolo-gia Exp Appl. 2012;144:123-33. View Article: http://onlinelibrary. wiley.com/doi/10.1111/j.1570-7458.2012.01249.x/full.

14. Liu XN, Liang P, Gao XW, Shi XY. Induction of the cytochrome P450 activity by plant allelochemicals in the cotton bollworm, Helicoverpa armigera (Hübner). Pestic Biochem Phys. 2006;84:127-34. View Article: http://www. sciencedirect.com/science/article/pii/S0048357505000878.

15. Celorio-Mancera MP, Ahn SJ, Heiko V, David GH. Transcriptional responses underlying the hormetic and detrimental effects of the plant secondary metabolite gossypol on the generalist herbivore Helicoverpa armigera. BMC Genomics. 2011;2:575. View Article: http://bmcgenomics.biomedcentral. com/articles/10.1186/1471-2164-12-575 PubMed: http://www.ncbi.nlm.nih. gov/pubmed/?term $=22111916$.

16. Stevens $J$, Snyder MJ, Koener JF, Feyereisen R. Inducible P450s of the CYP9 family from larval Manduca sexta midgut. Insect Biochem Mol Biol. 2000;30(7):559-68. View Article: http://www.sciencedirect.com/ science/article/pii/S0965174800000242 PubMed: http://www.ncbi.nlm.nih. gov/pubmed/?term $=10844248$.

17. Li H, Hao Z, Guan R, Miao X. Identification of differential expression genes associated with host selection and adaptation between two sibling insect species by transcriptional profile analysis. BMC Genomics. 2013;14(14):489-90. View Article: http://bmcgenomics.biomedcentral. com/articles/10.1186/1471-2164-14-582 PubMed: http://www.ncbi.nlm. nih.gov/pubmed/?term $=23984865$.

18. Li X, Baudry J, Berenbaum MR, Schuler MA. Structural and functiona evolution of insect CYP6B proteins: from specialist to generalist cytochrome P450. Proc Natl Acad Sci U S A. 2004:101(9):2939-44. View Article: http:// www.pnas.org/content/101/9/2939.long PubMed: http://www.ncbi.nlm.nih. gov/pubmed/?term $=14981232$.

19. Rupasinghe S, Wen Z, Chiu TL, Schuler MA. Helicoverpa zea CYP6B8 and CYP321A1: different molecular solutions to the problem of metabolizing plant toxins and insecticides. Protein Eng Des Sel. 2007;20(12):615-24. View Article: http://peds.oxfordjournals.org/content/20/12/615.long PubMed: http://www.ncbi.nlm.nih.gov/pubmed/?term = 18065401 .

20. Li X, Berenbaum MR, Schuler MA. Molecular mechanisms of metabolic resistance to synthetic and natural xenobiotics. Annu Rev Entomol. 2007;52: 231-53. View Article: http://www.annualreviews.org/doi/full/10.1146/ annurev.ento.51.110104.151104? url ver $=$ Z39.88-2003\&rfr id $=$ ori\%3Arid\%3Acrossref.org\&rfr_dat = cr_pub\%3Dpubmed PubMed: http:// www.ncbi.nlm.nih.gov/pubmed/?term $=16925478$.

21. Chiu TL, Wen Z, Rupasinghe SG, Schuler MA. Comparative molecular modeling of Anopheles gambiae CYP6Z1, a mosquito P450 capable of metabolizing DDT. Proc Natl Acad Sci U S A. 2008;105(26):8855-60. View Article: http://www.pnas.org/content/105/26/8855.long PubMed: http:// www.ncbi.nlm.nih.gov/pubmed/?term $=18577597$. 
22. Rewitz KF, Gilbert LI. Daphnia Halloween genes that encode cytochrome P450s mediating the synthesis of the arthropod molting hormone: Evolutionary implications. BMC Evol Biol. 2008;8(10):1-8. View Article: http:// bmcevolbiol.biomedcentral.com/articles/10.1186/1471-2148-8-60 PubMed: http://www.ncbi.nlm.nih.gov/pubmed/?term = 18298845 .

23. Feyereisen R. Evolution of insect P450. Biochem Soc Trans. 2006;34(6):12525. View Article: http://www.biochemsoctrans.org/content/34/6/1252.articleinfo PubMed: http://www.ncbi.nlm.nih.gov/pubmed/?term = 17073796.

24. Niwa R, Matsuda T, Yoshiyama T, Namiki T, Mita K, Fujimoto Y, et al. CYP306A1, a cytochrome P450 enzyme, is essential for ecdysteroid biosynthesis in the prothoracic glands of Bombyx and Drosophila. J Biol Chem. 2004;279(34): 35942-9. View Article: http://www.jbc.org/content/279/34/35942.long PubMed: http://www.ncbi.nlm.nih.gov/pubmed/?term $=15197185$.

25. Petryk A, Warren JT, Marqués G, Jarcho MP, Gilbert LI, Kahler J, et al. Shade is the Drosophila P450 enzyme that mediates the hydroxylation of ecdysone to the steroid insect molting hormone 20hydroxyecdysone. Proc Natl Acad Sci U S A. 2003;100(24):13773-8. View Article: http://www.pnas.org/content/100/24/13773.long PubMed: http:// www.ncbi.nlm.nih.gov/pubmed/?term $=14610274$.

26. Namiki T, Niwa R, Sakudoh T, Shirai K, Takeuchi H, Kataoka H. Cytochrome P450 CYP307A1/Spook: A regulator for ecdysone synthesis in insects. Biochem Biophys Res Commun. 2005;337(1):367-74. View Article: http:// www.sciencedirect.com/science/article/pii/S0006291X0502005X PubMed: http://www.ncbi.nlm.nih.gov/pubmed/?term = 16188237 .

27. Ono H, Rewitz KF, Shinoda T, Itoyama K, Petryk A, Rybczynski R, et al. Spook and spokier code for stage specific components of the ecdysone biosynthetic pathway in Diptera. Dev Biol. 2006;298(2):555-70. View Article: http://www.sciencedirect.com/science/article/pii/S0012160606009870 PubMed: http://www.ncbi.nlm.nih.gov/pubmed/?term = 16949568 .

28. Iga M, Kataoka H. Recent studies on insect hormone metabolic pathways mediated by cytochrome P450 enzymes. Biol Pharm Bull. 2012;35(6):838-43. View Article: https://www.jstage.jst.go.jp/article/bpb/35/6/35_b212002/_ article PubMed: http://www.ncbi.nlm.nih.gov/pubmed/?term = 22687472 .

29. Kim FR, Naoki Y, Michael BOC. Steroid hormone inactivation is required during the juvenile-adult transition in Drosophila. Dev Cell. 2011;19(6):895-902. View Article: http://www.sciencedirect.com/science/article/pii/S1534580710004740 PubMed: http://www.ncbi.nlm.nih.gov/pubmed/?term = 21145504 .

30. Sutherland TD, Unnithan GC, Andersen JF, Evans PH, Murataliev MB, Szabo LZ, et al. A cytochrome P450 terpenoid hydroxylase linked to the suppression of insect juvenile hormone synthesis. Proc Natl Acad Sci U S A. 1988;95(22): 12884-9. View Article: http://www.pnas.org/content/95/22/12884.long PubMed: http://www.ncbi.nlm.nih.gov/pubmed/?term = 9789009 .

31. Sutherland TD, Unnithan GC, Feyereisen R. Terpenoid omega-hydroxylase (CYP4C7) messenger RNA levels in the corpora allata: a marker for ovarian control of juvenile hormone synthesis in Diploptera punctate. J Insect Physiol. 2000;46(8):1219-27. View Article: http://www.sciencedirect.com/ science/article/pii/S0022191000000421 PubMed: http://www.ncbi.nlm.nih. gov/pubmed/?term $=10818249$.

32. Li X, Schuler MA, Berenbaum MR. Jasmonate and salicylate induce transcription of herbivore cytochrome P450 genes. Nature. 2002; 419(6908):712-5. View Article: http://www.nature.com/nature/journal/ v419/n6908/full/nature01003.html PubMed: http://www.ncbi.nlm.nih.gov/ pubmed/?term $=12384696$.

33. Gilbert LI, Rybczynski R, Warren JT. Control and biochemical nature of the ecdysteroidogenic pathway. Annu Rev Entomol. 2002;47:883-916. View Article: http://www.annualreviews.org/doi/full/10.1146/annurev.ento.47. 091201.145302? url_ver = Z39.88-2003\&rfr_id = ori\%3Arid\%3Acrossref.org\&rfr_ dat =cr_pub\%3Dpubmed PubMed: http://www.ncbi.n/m.nih.gov/pubmed/ ?term = 11729094 .

34. Kim FR, Michael BOC, Lawrence IG. Molecular evolution of the insect Halloween family of cytochrome P450s: phylogeny, gene organization and functional conservation. Insect Biochem Mol Biol. 2007;37(8):741-53. View Article: http://www.sciencedirect.com/science/article/pii/S0965174807000380 PubMed: http://www.ncbi.n/m.nih.gov/pubmed/?term = 17628274 .

35. Ai J, Zhu Y, Duan J, Yu Q, Zhang G, Wan F, Xiang ZH. Genome-wide analysis of cytochrome P450 monooxygenase genes in the silkworm, Bombyx mori. Gene. 2011;480(1-2):42-50. View Article: http://www.sciencedirect.com/ science/article/pii/S0378111911000928 PubMed: http://www.ncbi.nlm.nih. gov/pubmed/?term $=21440608$.

36. Yoshiyama T, Namiki T, Mita K, Kataoka K, Niwa R. Neverland is an evolutionally conserved Rieske-domain protein that is essential for ecdysone synthesis and insect growth. Development. 2006;133(13):2565-74. View Article: http://dev.biologists.org/content/133/13/2565.long PubMed: http:// www.ncbi.nlm.nih.gov/pubmed/?term = 16763204 .

37. Helvig C, Koener JF, Unnithan GC, Feyereisen R. CYP15A1, the cytochrome P450 that catalyzes epoxidation of methyl farnesoate to juvenile hormone III in cockroach corpora allata. Proc Natl Acad Sci U S A. 2004;101(12):4024-9. View Article: http://www.pnas.org/content/101/12/4024.long PubMed: http://www. ncbi.nlm.nih.gov/pubmed/?term = 15024118 .

38. Aragon S, Claudinot S, Blais C, Maibeche M, Dauphin-Villemant C. Molting cycle-dependent expression of CYP4C15, a cytochrome P450 enzyme putatively involved in ecdysteroidogenesis in the crayfish, Orconectes limosus. Insect Biochem Mol Biol. 2002;32(2):153-9. View Article: http://www. sciencedirect.com/science/article/pii/S0965174801000959 PubMed: http:// www.ncbi.nlm.nih.gov/pubmed/?term = 11755057

39. Cohen MB, Schuler MA, Berenbaum MR. A host-inducible cytochrome P450 froma host-specific caterpillar: molecular cloning and evolution. Proc Natl Acad Sci U S A. 1992:89:10920-4. View Article: http://www. pnas.org/content/89/22/10920.long PubMed: http://www.ncbi.nlm.nih. gov/pubmed/?term $=1279697$.

40. Hung CF, Berenbaum MR, Schuler MA. Isolation and characterization of CYP6B4, furanocoumarin-inducible cytochrome P450 from a polyphagous caterpillar (Lepidoptera: Papilionidae). Insect Biochem Mol Biol. 1997;27(5):377-85. View Article: http://www.sciencedirect.com/ science/article/pii/S096517489700009X PubMed: http://www.ncbi.nlm. nih.gov/pubmed/?term $=9219364$.

41. Hung CF, Holzmacher R, Connolly E, Berenbaum MR, Schuler MA. Conserved promoter elements in the CYP6B gene family suggest common ancestry for cytochrome P450 monooxygenases mediating furanocoumarin detoxification. Proc Natl Acad Sci U S A. 1996;93(22):12200-5. View Article: http://www.pnas.org/content/93/22/12200.long PubMed: http://www.ncbi. nlm.nih.gov/pubmed/?term $=8901557$.

42. Wang RL, Li J, Staehelin C, Xin XW, Su YJ, Zeng RS. Expression analysis of two P450 monooxygenase genes of the tobacco cutworm moth (Spodoptera litura) at different developmental stages and in response to plant allelochemicals. J Chem Ecol. 2015;41(1):111-9. View Article: http://link. springer.com/article/10.1007\%2Fs10886-014-0540-z PubMed: http://www. ncbi.nlm.nih.gov/pubmed/?term = 25547988 .

43. Pan YO, Guo HL, Gao XW. Carboxylesterase activity, cDNA sequence, and gene expression in malathion susceptible and resistant strains of the cotton aphid, Aphis gossypii. Comp Biochem Physiol B. 2009;152(3):266-70. View Article: http://www.sciencedirect.com/science/article/pii/S1096495908003801 PubMed: http://www.ncbi.nlm.nih.gov/pubmed/?term = 19110065 .

44. Wen Z, Rupasinghe S, Niu G, Berenbaum MR, Schuler MA. CYP6B1 and CYP6B3 of the black swallowtail (Papilio polyxenes): adaptive evolution through subfunctionalization. Mol Biol Evol. 2006;23(12):2434-43. View Article: http://mbe.oxfordjournals.org/content/23/12/2434.long PubMed: http://www.ncbi.nlm.nih.gov/pubmed/?term = 16984951 .

45. Wen Z, Zeng RS, Niu G, Berenbaum MR, Schuler MA. Ecological significance of induction of broad-substrate P450s by natural and synthetic inducers in Helicoverpa zea. J Chem Ecol. 2009;35(2):183-9. View Article: http://link. springer.com/article/10.1007\%2Fs10886-009-9598-4 PubMed: http://www. ncbi.nlm.nih.gov/pubmed/?term = 19198946.

46. Warren JT, Yerushalmi Y, Shimell MJ, O'Connor MB, Restifo LL, Gilbert LI. Discrete pulses of molting hormone, 20-hydroxyecdysone, during late larval development of Drosophila melanogaster: correlations with changes in gene activity. Dev Dyn. 2006;235(2):315-26. View Article: http://onlinelibrary.wiley. com/doi/10.1002/dvdy.20626/abstract PubMed: http://www.ncbi.nlm.nih. gov/pubmed/?term $=16273522$.

47. Grabherr MG, Haas BJ, Yassour M, Levin JZ, Thompson DA, Amit I, et al. Fulllength transcriptome assembly from RNA-Seq data without a reference genome. Nat Biotechnol. 2011;29(7):644-52. View Article: http://www.nature. com/nbt/journal/v29/n7/full/nbt.1883.html PubMed: http://www.ncbi.nlm. nih.gov/pubmed/?term $=21572440$

48. Kriventseva EV, Tegenfeldt F, Petty TJ, Waterhouse RM, Simao FA, Pozdnyakov IA, et al. OrthoDB v8: update of the hierarchical catalog of orthologs and the underlying free software. Nucleic Acids Res. 2015;43: D250-256. View Article: http://nar.oxfordjournals.org/content/43/D1/D250 PubMed: http://www.ncbi.nlm.nih.gov/pubmed/25428351.

49. Simão FA, Waterhouse RM, loannidis P, Kriventseva EV, Zdobnov ZM. BUSCO: assessing genome assembly and annotation completeness with single-copy orthologs. Bioinformatics. 2015;31(19):3210-2. View Article: 
http://busco.ezlab.org/files/BUSCO-Simao-Waterhouse-Bioinformatics-2015. pdf PubMed: http://www.ncbi.nlm.nih.gov/pubmed/26059717.

50. Katoh K, Toh H. Recent developments in the MAFFT multiple sequence alignment program. Brief Bioinformatics. 2008;9(4):286-98. View Article: http://bib.oxfordjournals.org/content/9/4/286 PubMed: https://www.ncbi. nlm.nih.gov/pubmed/18372315.

51. Tamura K, Stecher G, Peterson D, Filipski A, Kumar S. MEGA6: molecular evolutionary genetics analysis version 6.0. Mol Biol Evol. 2013;30(12):2725-9. View Article: http://mbe.oxfordjournals.org/content/30/12/2725.short PubMed: https://www.ncbi.nlm.nih.gov/pubmed/24132122.

52. Mortazavi A, Williams BA, McCue K, Schaeffer L, Wold B. Mapping and quantifying mammalian transcriptomes by RNA-Seq. Nat Meth. 2008;5(7):6218. View Article: http://www.nature.com/nmeth/journal/v5/n7/full/nmeth.1226. html PubMed: http://www.ncbi.nlm.nih.gov/pubmed/?term = 18516045.

53. Beissbarth T, Speed TP. GOstat: find statistically overrepresented Gene Ontologies within a group of genes. Bioinformatics. 2004;20(9):1464-5. View Article: http://bioinformatics.oxfordjournals.org/content/20/9/1464.long PubMed: http://www.ncbi.n/m.nih.gov/pubmed/?term = 14962934 .

54. Benjamini Y, Drai D, Elmer G, Kafkafi N, Golani I. Controlling the false discovery rate in behavior genetics research. Behav Brain Res. 2005;125(1-2):279-84. View Article: http:/www.sciencedirect.com/science/article/pii/S0166432801002972 PubMed: http://www.ncbi.nlm.nih.gov/pubmed/?term $=11682119$.

55. Vandesompele J, De Preter K, Pattyn F, Poppe B, Van Roy N, De Paepe A, Speleman F. Accurate normalization of real-time quantitative RT-PCR data by geometric averaging of multiple internal control genes. Genome Biol. 2002;3(7):research0034.1-0034.11. View Article: http://genomebiology. biomedcentral.com/articles/10.1186/gb-2002-3-7-research0034 PubMed: https://www.ncbi.nlm.nih.gov/pubmed/12184808.

56. Andersen $\mathrm{CL}$, Jensen $\mathrm{JL}$, Orntoft TF. Normalization of real-time quantitative reverse transcription-PCR data: a model-based variance estimation approach to identify genes suited for normalization, applied to bladder and colon cancer data sets. Cancer Res. 2004;64:5245-50. View Article: http://cancerres. aacrjournals.org/content/64/15/5245.long PubMed: https:/www.ncbi.nlm. nih.gov/pubmed/15289330.

\section{Submit your next manuscript to BioMed Central and we will help you at every step:}

- We accept pre-submission inquiries

- Our selector tool helps you to find the most relevant journal

- We provide round the clock customer support

- Convenient online submission

- Thorough peer review

- Inclusion in PubMed and all major indexing services

- Maximum visibility for your research

Submit your manuscript at www.biomedcentral.com/submit 